\title{
Religious Belief and Firm R\&D Investment
}

\author{
Hailipitimu Aibibula, Gege Wang, Chengcheng Zhang \\ School of Business Administration, South China University of Technology, Guangzhou, China \\ Email: hailipitimu2017@outlook.com
}

How to cite this paper: Aibibula, H., Wang, G.G. and Zhang, C.C. (2017) Religious Belief and Firm R\&D Investment. Technology and Investment, 8, 142-150. https://doi.org/10.4236/ti.2017.82012

Received: March 29, 2017

Accepted: May 24, 2017

Published: May 27, 2017

Copyright (c) 2017 by authors and Scientific Research Publishing Inc. This work is licensed under the Creative Commons Attribution International License (CC BY 4.0).

http://creativecommons.org/licenses/by/4.0/ (c) (i) Open Access

\begin{abstract}
In order to explore the influencing mechanism of entrepreneur's religious belief on firm R\&D investment, this paper constructs a model on the basis of a game between an entrepreneur and researchers over the control right of R\&D projects. We take researchers' concern on free inquiry as an intermediate variable. We find that the researcher's attention of free inquiry has a critical impact on the relationship between entrepreneur's religious belief and firm R\&D investment. Specifically, our results show that no matter how much the entrepreneur hates risk, the firm will increase R\&D investment only when the researchers pay enough attention to free inquiry. On the contrary, if researchers do not attach any importance to the academic spirit which is "free inquiry", corporate $\mathrm{R} \& \mathrm{D}$ investment is decreased with the enhancing of the degree of entrepreneur's risk aversion, namely the entrepreneurs who are religious, risk-aversive may try to reduce the R\&D investment.
\end{abstract}

\section{Keywords}

Entrepreneur's Religious Belief, Risk Aversion, Researchers, the Spirit of Free Inquiry, R\&D Investment

\section{Introduction}

Religion has a significant impact on the spiritual awareness and ideas of believers such as values as an important dimension of social culture [1]. Studies have shown that the proportion of religious believers in China showed a clear upward trend in recent years [2], and the number of religious believers in private entrepreneurs has gradually increased [3]. Iannaccone believes that the values which incorporate religious beliefs will influence the thinking modes and behavioral decisions of entrepreneurs in subtle process, and then may affect the formulation and implementation of corporate strategic decisions [4]. Current scholars have begun to pay attention to the role of religious beliefs on corporate behavior, and initially carried out the relevant research. For example, Hilary and Hui argue 
that the beliefs of entrepreneur affect corporate decision-making [5]. Based on the four aspects such as spiritual level, institutional level, behavioral level and material level, Lin Liqiang has explored the forms and mechanisms of integrating religious belief into corporate culture development [6]. Zhou Yi and $\mathrm{Hu} \mathrm{An}-$ ning show that religious beliefs could promote corporate charitable donations with the survey results on Wenzhou private entrepreneurs [7]. Wang Wenlong's research affirmed the view, and he also introduced a new variable which is the political identity. He has pointed out that if private entrepreneurs do not have a political identity, the positive relationship between religious beliefs and corporate charitable acts will be more obvious and intense [8].

The social security function of religious belief is one of the ways people choose to avoid risks [2]. Ferguson' study argues that people with religious beliefs often tend to choose the risk aversive attitudes and standpoint, they always tend to the behavioral acts which are less risky even without risks [9]. Jiang found that compared with the founder of the family business without religious beliefs, the founder of family business who has religious belief more strongly tends to avoid risks [10]. There are also some studies showing that some risk aversive individuals are affected by the anxiety at first, and then their normal life was disrupted, so they choose to believe in religion to seek psychological relief and comfort, so that the risk they faced is reduced. Lei et al. studied the role of religious belief in the corporate investment behavior through direct survey data, the results show that the entrepreneurs believe that the eastern religious beliefs are more inclined to the less risky-relational investment [11]. Combining the cultural traditions of Chinese society and the uncertainties in the transitional society, we argue that entrepreneurs who have religious beliefs ${ }^{1}$ are risk aversive, and they who have a strong aversion to risk often tend to choose the business activities which those risks are as low as possible to participate and implement.

With the rapid development of science and technology and the gradual improvement of China's economic system and institutions, the market competition is becoming more and more intense. Thus the demand of consumers is becoming more diversified and individualized increasingly, and it puts forwarded high level demand and expectations on the product quality in turn. Especially in the current transitional environment, compared with state-owned enterprises, China's private enterprises are facing more severe challenges and pressures. First of all, the market environment and government behavior is an important part of the private enterprises' institutional environment, the institutional environment of private enterprises indeed needs to be further improved due to the historical reasons and reality in the current economic background [12]; Secondly, the financial system and the market are not sound yet, information asymmetry and other factors, private enterprises are facing financing difficulties because of factors such as transaction costs and information asymmetry and so on, it may ${ }^{1}$ The existing literature divides the religious beliefs of entrepreneurs into oriental religion (mainly Buddhism and Taoism) and Western religion (mainly Islam and Christianity). For the sake of simplicity of our analysis, the entrepreneurs' religious beliefs in this article only considers oriental religion. 
bring a great obstacle to the future development of enterprises [13]. Finally, state-owned enterprises have natural resource endowments and status advantages, so they are more access to policy subsidies and support, while the private enterprises need to seek other ways for obtaining resources [14]. In order to seek a place successfully in the fierce competition in the market and master the initiative, private enterprises must carry out long-term continuous $R \& D$ investment activities to enhance the ability of independent innovation so as to maintain the core competitiveness of enterprises. Therefore, enterprises' R\&D investment strategy decision is particularly important.

However, we can see from the existing research that scholars have not paid full attention to the relationship between entrepreneurs' religious beliefs and corporate $\mathrm{R} \& \mathrm{D}$ investment, and the related research literatures are rare. $\mathrm{R} \& \mathrm{D}$ investment requires a lot of money and staff input, and it' payback period is quite long, coupled with the possibility of failure in the $\mathrm{R} \& \mathrm{D}$, so it is full of great risks. Of course, once the $\mathrm{R} \& \mathrm{D}$ investment activities were succeeded, it will bring great benefits to the enterprise. Zhu and $\mathrm{Li}$ pointed out that risk attitudes and preferences have a significant impact on the R\&D strategic choice of firms [15]. It can be seen from the relation above that the entrepreneurs beliefs believe in religion have a strong sense of aversion on risk, and the $\mathrm{R} \& \mathrm{D}$ activities with high degree of uncertainty and risks will bring great physical and psychological pressures to religious entrepreneurs, also increase their anxiety simultaneously, So they are often reluctant to conduct high-risky R\&D investment activities. In fact, the religious entrepreneurs attach much importance to the use and maintenance of social interpersonal relationships because of the traditional culture advocated by "humanism", will also try to get resources and carry out business activities smoothly through this relationship. This kind of investment activities based on relationships are characterized by less risks and low uncertainties, so the risk aversive entrepreneurs (that have religious beliefs) are more inclined to carry out such investment activities [11]. In fact, scientific researchers are the main conductors of enterprises' R\&D project, their efforts and input determine the effectiveness of enterprises' R\&D projects to a large extent. Aghion showed that these researchers experienced a certain academic training have a strong sense of controlling innovation and the spirit of free inquiry [16], This kind of spirit of free exploration drives them to try things boldly in ways they think sound according to their own thought, adventurous researchers are willing to challenge those projects which are highly risky and highly uncertain. In other words, as long as researchers think that a $\mathrm{R} \& \mathrm{D}$ project can give them a full play, they will enthusiastically immerse in the $\mathrm{R} \& \mathrm{D}$ project, which not only make the researchers to enjoy the fun of the process, but also increase their own academic values [16].

On the contrary, entrepreneurs who believe in religion have a strong sense of risk aversion, they are reluctant to try $R \& D$ projects that are relatively risky and quite uncertain, and also may interfere with the work of researchers related to R\&D projects. This will affect researchers' enthusiasm directly and bring a certain negative effect to the researchers, resulting in their work efforts and extent 
of focus on projects is greatly reduced. It can be seen obviously that in the private enterprises managed by the entrepreneurs who have religious belief, when the company plans to development and conduct research projects, there will be a interest game based on the right of controlling the $R \& D$ projects between religious entrepreneur and researchers, because entrepreneurs and researchers hold different attitudes toward the risk of R\&D projects. Therefore, from the perspective of the influence of entrepreneurs' religious belief on corporate strategic behavior and based on the spirit of free inquiry of researchers, this paper focuses on exploration and analysis of the role and mechanism of entrepreneurs' religious belief on the $R \& D$ investment of enterprises, so as to provide the $R \& D$ strategic decision of private enterprises with practical guidance and theoretical references via constructing the game model.

\section{Problem Description and the Construction of Basic Game Model}

\subsection{Basic Hypothesis}

We assume that there is a private enterprise to carry out a research and development project. This $\mathrm{R} \& \mathrm{D}$ project can not only bring a considerable market value to entrepreneurs and shareholders, but also help researchers who undertake the $R \& D$ project to enhance their academic value. For simplicity, this paper assumes that the $\mathrm{R} \& \mathrm{D}$ projects bring the same market value and academic value, both are $e I$. Among them, we use $e$ as the degree of effort for researchers, and $I$ which is mainly depended on entrepreneur is the total investment for the R\&D project. In view of the heterogeneity of each person's knowledge, information accumulation and the asymmetric information, entrepreneurs are different for the extent of understanding different $R \& D$ projects, so the organizational skills for different R\&D projects are also different. For the simplicity of our analysis, based on the research of Aghion et al. [16], we assume that there are only two cases of entrepreneur' understanding of R\&D projects, that is understanding and not understanding. Therefore, their organizational capacity in different cases is distributed as:

$$
\delta= \begin{cases}n, & \text { when the entrepreneurs understand R \& D projects } \\ -n, & \text { when the entrepreneurs don't understand R \& D projects }\end{cases}
$$

This paper assumes that the variation of market value of the $R \& D$ project is positively related to the organizational capacity of the entrepreneur, because we believe that the intervention of entrepreneurs who have better understanding of $R \& D$ projects on the specific operation of projects will increase the value of the $\mathrm{R} \& \mathrm{D}$ project; On the contrary, there will be an opposite effect. So, when the entrepreneur intervenes in the $\mathrm{R} \& \mathrm{D}$ project, the market value of the project is $e I(1+\delta)$. For each concrete $\mathrm{R} \& \mathrm{D}$ project, both researchers and entrepreneurs will have a pre-estimated probability which we assume is equal, although we generally cannot determine the value of $\delta$. It is specifically as follows:

$$
P_{s}(\delta=n)=P_{s}(\delta=-n)=\frac{1}{2}=P_{f}(\delta=n)=P_{f}(\delta=-n)
$$


Among them, $P_{s}(\cdot)$ and $P_{f}(\cdot)$ were the distribution of $\delta$ for researchers and entrepreneurs, this distribution is common information to both parties. According to the analysis of Aghion et al., this paper assumes that entrepreneurs will use less authoritarian schemes. Only when the entrepreneur is convinced that he understands the research and development project well, that is, when the $\delta=n$, then the project will be intervened by entrepreneur; Otherwise, when $\delta=-n$, entrepreneurs will not intervene in the project, researchers will naturally get the control of $\mathrm{R} \& \mathrm{D}$ project at this time.

In short, this model mainly describes the game on the R\&D investment and the right of controlling projects between the religious entrepreneur and the researcher. The game process is as follows: 1 ) the size of $\mathrm{R} \& \mathrm{D}$ investment $I$ is determined by entrepreneurs; 2) as the specific operator of the R\&D project, the researcher will decide his own effort $e$ according to the existing information and start the related research and development. However, the religious entrepreneurs with risk aversion (the degree of risk aversion is recorded as $k$ ) will try to intervene and interfere with the work of researchers who attach a great importance to the spirit of free exploration; 3) Entrepreneurs with risk aversion can determine the degree of their understanding of $R \& D$ projects by observing the progress of $\mathrm{R} \& \mathrm{D}$ projects. As long as the entrepreneur is convinced that he is well aware of the project, he will begin to intervene in order to try to make the R\&D projects go as he wishes; 4) the R\&D projects are completed.

\subsection{Construction of Game Model}

\subsubsection{Revenue Analysis of Researchers}

Researchers are the direct operators of $\mathrm{R} \& \mathrm{D}$ projects, and the benefit he gains from which is the academic value of the program (el). When the religious entrepreneurs with risk aversion interfere in scientific research work, the work enthusiasm of researchers who like the free academic atmosphere and attach great importance to the spirit of free inquiry will be hit, so they will get negative effects $k f e$ (Where parameter $k$ represents the degree of risk aversion of entrepreneurs with religious beliefs, $f$ and $e$ are the degree of researchers' attention to the spirit of free inquiry and their efforts respectively); Otherwise, the utility of the researchers will not be lost. This implicates that, in the case of other conditions unchanged, when the entrepreneurs intervene in the research work, the higher the degree of entrepreneurs' risk aversion and the degree of efforts of researchers, or the degree of attention of the researchers to the free exploration, the greater the negative effect of the researchers will be obtained. So then, the cost researchers have to pay because of the efforts they make as below:

$$
C(e)=\frac{e^{2}}{2 \gamma} \quad(\gamma>0)
$$

In conclusion, the expected net income of the researcher is

$$
\begin{aligned}
E_{s} & =P_{f}(\delta=n)(e I-k f e)+P_{f}(\delta=-n) e I-C(e) \\
& =e I-\frac{1}{2} k f e-\frac{e^{2}}{2 \gamma}
\end{aligned}
$$


According to the maximum condition of first derivative $\frac{\partial E_{s}}{\partial e}=0$, we can get the optimal degree of researchers' efforts that is

$$
e^{*}=\gamma\left(I-\frac{1}{2} k f\right)
$$

we can see with the formula (5) that, only when $I>\frac{1}{2} k f$, then $e^{*}>0$. That is the marginal increment of the academic value of the $R \& D$ project is larger than the expected marginal increment of the negative effect of the researchers is the necessary and sufficient conditions for researchers to undertake scientific research tasks and participate in $\mathrm{R} \& \mathrm{D}$ projects.

\subsubsection{Decisions of $R \& D$ Investment}

An entrepreneur who has a risk aversion determines the size of the total investment $I$ of the R\&D project according to the conditions of the formula (5), and then ultimately achieves the maximization of company's revenue. As mentioned above, only when the entrepreneur believes that they understand the R\&D project quite well, they will choose to intervene in the $R \& D$ so as to reduce the risk and uncertainty of R\&D projects, so the fundamental purpose of entrepreneurs to intervene in R\&D projects is increasing the value of which to $e I(1+\delta)$. In addition, the $\mathrm{R} \& \mathrm{D}$ projects need to pay a certain cost as well as other investment projects do. This paper assumes that the investment cost of the project is proportional to the total input $I$, and the cost of unit funds is $v$. Based on the above analysis, the expected net income from the R\&D project is:

$$
\begin{aligned}
& E_{f}=P_{f}(\delta=n)(1+\delta) e I+P_{f}(\delta=-n) e I-v I \\
& =I\left(e+\frac{1}{2} n e-v\right) .
\end{aligned}
$$

Via substituting Equation (5) into Equation (6), we get the expected net income is equal to

$$
E_{f}=I\left[\gamma\left(1+\frac{1}{2} n\right)\left(I-\frac{1}{2} k f\right)-v\right]
$$

Through the maximum condition of first derivative $\frac{\partial E_{f}}{\partial I}=0$, we can also get the optimal R\&D investment is

$$
I^{*}=\frac{v}{\gamma(n+2)}+\frac{1}{4} k f
$$

Below is available from (8)

$$
\frac{\partial I^{*}}{\partial k}=\frac{1}{4} f
$$

It is easily derived from Formula (9) that $\frac{\partial I^{*}}{\partial k}>0$, just only when $f>0$. It can be seen that for the enterprises plan to carry out R\&D investment, in order to consolidate their core competitiveness and maintain the technological advan- 
tages, as long as the concrete performers of R\&D project pay enough attention to free inquiry and is inclined to academic freedom $(f>0)$, companies will increase $\mathrm{R} \& \mathrm{D}$ investment, regardless of the degree of entrepreneurs' risk aversion; On the other hand, if researchers do not focus on free inquiry and academic freedom, then with the increasing of the extent of religious entrepreneurs' risk aversion, the $\mathrm{R} \& \mathrm{D}$ investment will be reduced accordingly. That is because entrepreneurs want to reduce $\mathrm{R} \& \mathrm{D}$ investment so as to reduce the risks and uncertainty that R\&D projects may bring. Based on the above analysis, this paper concludes:

The influence of entrepreneurs' religious beliefs on the R\&D investment of enterprises is moderated by "the spirit of free inquiry" of scientific researchers. If researchers do not have "the spirit of free inquiry" and attach importance to academic freedom, the religious entrepreneurs with risk aversion will try to cut R\&D investment. In addition, it can be found by analyzing Equation (5), the risk aversion of entrepreneurs who have religious beliefs also reduces the effort $(e)$ of researchers, and the extent of the reduction is influenced by $f$. That is, the reduction rate increases as $f$ becomes larger, thereby it will finally result in a decrease of market income eI. So, entrepreneurs need to consider this kind of effect that brought by the religious beliefs of entrepreneurs when they decided to increase or reduce the $\mathrm{R} \& \mathrm{D}$ investment. In other words, the general highly educated researchers are more inclined to a strong-free atmosphere in exploration, and this atmosphere requires entrepreneurs to pay more costs for their intervention. If the extent of entrepreneurs' risk aversion enlarges, and entrepreneurs try to intervene in the R\&D projects, they should also increase the total investment $I$ in $\mathrm{R} \& \mathrm{D}$ projects to ensure the maximization of net business income.

\section{Conclusions and Discussions}

Whether the religious belief of entrepreneurs will play an influential role in the $\mathrm{R} \& \mathrm{D}$ investment decision-making, and what is its mechanism? The existing researches have not yet given a clear answer. In order to solve this problem, this paper constructs the game model between entrepreneurs and researchers and introduces the variable called "the spirit of free inquiry" to explore this mechanism. It is shown from the analysis of the model that the extent of researcher' attention paid to "the spirit of free inquiry" directly determines the relational role between the religious belief and corporate $\mathrm{R} \& \mathrm{D}$ investment role. As long as the researchers pay enough attention to free academic exploration, the religious beliefs of entrepreneurs will actively promote enterprises to increase R\&D investment. That is, enterprises will increase $R \& D$ investment regardless of how much the degree of entrepreneurs' risk aversion is. On the contrary, if the researchers do not attach importance to the academic spirit "free inquiry", corporate R\&D investment will decrease with the increasing of the degree of entrepreneurs' risk aversion. Namely, religious entrepreneurs who are risk aversive will try to cut $\mathrm{R} \& \mathrm{D}$ investment. The study related to religion in China is mainly focused on the field of politics and sociology, in recent years, some scholars have introduced the 
religion into the management field and tried to explore the path and mechanism of their influence on the corporate behavior [17] [18] [19]. This article will enrich and develop the application research of the impact of religious belief on corporate behavior.

As the pace of China's efforts to promote government-led innovation to enterprise-led innovation is accelerating, the independent innovation of private enterprises is becoming more and more important in the implementation of new innovation and development strategies as the main body of national new innovation activities [20]. In other words, independent innovation is the only way for private enterprises to achieve sustainable development [21], and R\&D activity is the key to enterprises conduct technological innovation, and achieves transformation and upgrading. Therefore, this study has important practical significance and reference value for the successful development of R\&D activities of Chinese private enterprises, especially those are managed by entrepreneurs who believe in religion. Corporate $R \& D$ decisions are made under the direct role of entrepreneurs, our research shows that even if the religious beliefs of entrepreneurs may intervene in the company's $R \& D$ projects, but their risk aversion does not necessarily constraint and inhibit corporate $\mathrm{R} \& \mathrm{D}$ behavior, as long as the research team of enterprises advocates and the pursues "the spirit of free inquiry", enterprises will increase R\&D investment continually, instead.

In addition, the researchers of enterprises are the direct undertakers first-line operators of $\mathrm{R} \& \mathrm{D}$ projects, researchers have to adhere to and be determined to "the spirit of free inquiry" as a basis and guarantee of conducting R\&D projects smoothly. For a long time, private enterprises are more concerned on expanding the R\&D investment and scale, and did not pay enough attention to cultivation of "the spirit of free inquiry" of researchers. According to the research results of this paper, enterprises should provide talent resource foundation and intellectual support for R\&D activities. More importantly, it is necessary for enterprises and even the whole society to improve the internal institutions and management system further, create a more strong academic atmosphere of "free exploration", actively encourage researchers and the R\&D team to carry forward "the spirit of free inquiry", providing the most extensive space for researchers to show their talent and play the role willingly.

\section{References}

[1] Ruan, R.P., Zheng, F.T. and Liu, L. (2014) Religious Believing and Social Conflict: Origin or Instrument? China Economic Quarterly, No. 2, 793-816.

[2] Zheng, F.T., Ruan, R.P. and Liu, L. (2010) Risk, Social Security and Religious Beliefs. China Economic Quarterly, 9, 829-850.

[3] Li, X.P. and Yang, F.G. (2009) The Relationship between Christian Ethics and Social Trust. China Minzu Journal, No. 6.

[4] Iannaccone, L.R. (1998) Introduction to the Economics of Religion. Journal of Economic Literature, 36, 1465-1495.

[5] Hilary, G. and Hui, K.W. (2009) Does Religion Matter in Corporate Decision Making in America? Journal of Financial Economics, 93, 455-473. 
[6] Lin, L.Q. (2010) My Humble Opinion on Religious Belief of Private Entrepreneur and Enterprise Culture Construction. Economic Management, No. 3, 86-91.

[7] Zhou, Y. and Hu, A.N. (2014) Capital with Faith: A Study on the Charitable Giving Behavior of Wenzhou Private Entrepreneurs. Studies in China Sociology, No. 1, 57-81.

[8] Wang, W.L., Jiao, J., Jin, Z.M., et al. (2015) CEO's Religious Belief and Corporate Philanthropic Giving. Journal of Tsinghua University (Science \& Technology), No. 4, 443-451.

[9] Ferguson, M.A., Valenti, J.M. and Melwani, G. (1991) Communicating with Risk Takers: A Public Relations Perspective. Public Relations Research Annual, 3, 195224. https://doi.org/10.1207/s1532754xjprr0301-4_10

[10] Jiang, F., Jiang, Z., Kim, K.A., et al. (2015) Family-Firm Risk-Taking: Does Religion Matter? Journal of Corporate Finance, 33, 260-278.

[11] Lei, G.Y., Liu, M. and Cao, Y.L. (2016) Religious Beliefs, Political Identity and Firm Investment Preferences. Journal of Finance and Economics, No. 6, 110-120.

[12] Liao, K.R. and Chen, S.Y. (2011) The Influence of Institutional Environments on Private Enterprise's R\&D Investment: An Empirical Study. Studies in Science of Science, No. 9, 1342-1348.

[13] Chen, S.Y., Jing, R.T., Long, X.N., et al. (2010) An Empirical Study on the Influence of Private Entrepreneur's Social Relations Capital on the R\&D Investment Decisions. Management World, No. 1, 88-97.

[14] Jiang, Y.W., Huang Y. and Xu, W. (2012) The Political Connections and R\&D of Private Enterprises Based on the Perspective of Marketization Degree. Science Research Management, No. 10, 48-55.

[15] Zhu, B. and Li, L.L. (2014) An Empirical Analysis of the Impact of Public Subsidies on Private Enterprise's R\&D Investment. Society, No. 4, 165-186.

[16] Aghion, P. and Tirole, J. (1997) Formal and Real Authority in Organizations. Journal of Political Economy, 105, 1-29. https://doi.org/10.1086/262063

[17] He, J.G. (2015) Religion and Capital Market Research in Accounting: Literature Review. Studies in Accounting, No. 11, 49-54.

[18] Zhang, S.R. (2016) Influences of Administrator Characteristics on the Behaviors of Agricultural Corporate Social Responsibility-Based on the Date from Five Provinces. Economic Survey, No. 4, 121-126.

[19] He, X.P., Dai, Y.Y. and Weng, R.Y. (2016) Religion, Risk Averse and Capital Structure Adjustment. Journal of Shanxi University of Finance and Economics, No. 9, $1-12$.

[20] Yang, Z., Yan, Z.B., et al. (2015) The Impact of R\&D Investments in State-Owned Enterprises on the Innovative Behavior of Private-Owned Enterprises. Science Research Management, No. 4, 82-90.

[21] Liu, Y.Q., Zhao, S.Q. and Liu, Y.H. (2007) Independent Innovation and the Upgrade of Brand Competitiveness of Private Enterprises. Finance \& Trade Economics, No. 1, 76-82. 
Submit or recommend next manuscript to SCIRP and we will provide best service for you:

Accepting pre-submission inquiries through Email, Facebook, LinkedIn, Twitter, etc. A wide selection of journals (inclusive of 9 subjects, more than 200 journals)

Providing 24-hour high-quality service

User-friendly online submission system

Fair and swift peer-review system

Efficient typesetting and proofreading procedure

Display of the result of downloads and visits, as well as the number of cited articles Maximum dissemination of your research work

Submit your manuscript at: http://papersubmission.scirp.org/

Or contact ti@scirp.org 